\title{
Increased Expression of Erythropoietin Receptor in 1-Methyl-4- Phenyl-1, 2, 3, 6-Tetrahydropyridine-Induced Parkinsonian Model
}

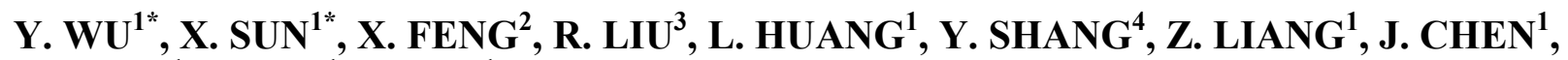

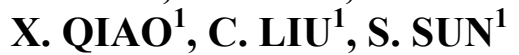 \\ * These authors contributed equally.
}

${ }^{1}$ Department of Neurology, Union Hospital, Tongji Medical College, Huazhong University of Science and Technology, Wuhan, China, ${ }^{2}$ Department of Anatomy, Sanxia Medical College, Chongqing, China, ${ }^{3}$ Department of Anatomy, Tongji Medical College, Huazhong University of Science and Technology, Wuhan, China, ${ }^{4}$ Department of Anesthesiology, Union Hospital, Tongji Medical College, Huazhong University of Science and Technology, Wuhan, China

Received October 23, 2008

Accepted March 25, 2009

On-line June 19, 2009

\section{Summary}

Erythropoietin (EPO), known for its role in erythroid differentiation, has been suggested to have a direct protective role against a variety of neurotoxic insults. In the present study, we investigated the expression of EPO receptor (EPOR) and the number of EPORpositive cells in three encephalic regions (ventral mesencephalon, striatum, cortex) following lesion induced by 1-methyl-4-phenyl1,2,3,6-tetrahydropyridine (MPTP). C57BL/6 mice underwent intraperitoneal injection of MPTP at $24 \mathrm{~h}$ intervals for 5 days, and their brains were examined $1,2,4,7,14$ or 21 days after the last injection. Western blot and immunohistochemistry analysis revealed that EPOR was dramatically up-regulated in the ventral mesencephalon, 4 days after MPTP insult until the day 21 . In contrast, there was a baseline level of EPOR in the striatum and cortex. At subsequent time points after MPTP injury, the levels of EPOR in the two regions were not statistically different compared with those in normal animals. These results suggest that the regional specific up-regulation of EPOR at an early stage after MPTP stimulus may represent a pro-survival mechanism against neurotoxin injury in Parkinsonian model.

\section{Key words}

EPOR • MPTP • C57BL/6 mice • Parkinson disease • Ventral mesencephalon

\section{Corresponding author}

S. Sun, Department of Neurology, Union hospital, Tongji Medical College, Huazhong University of Science and Technology, Wuhan 430022, P. R. China. Fax: +86-27-85726925. E-mail: sun_shenggang@163.com

\section{Introduction}

Erythropoietin (EPO) is a cytokine that acts on erythroid progenitor proliferation and differentiation. It has been clearly demonstrated that EPO is a potent promoter of neuronal survival. Studies in vitro provided the information related to the molecular pathways involved in EPO action. These data showed that EPO might have a direct protective role against a variety of neurotoxic insults, such as hypoxic conditions (Marti et al. 1996), glutamate toxicity (Morishita et al. 1997), freeradical injury (Chong et al. 2003), and exposure to neurotoxic agents (Villa et al. 2003, Shang et al. 2007). We have demonstrated that EPO substantially reduced 1-methyl-4-phenylpyridinium-induced cellular death in PC12 cells via its antioxidant and antiapoptotic properties (Wu et al. 2007a,b).

EPO, a cytokine belonging type I superfamily, exerts its neuroprotective function by binding to its receptor (EPOR). In concert with the strong empirical basis for EPO's neuroprotective mechanisms, ample evidence suggests that the endogenous EPO and EPOR system is involved in neuronal protection. The abundant expression of EPOR in the central nervous system (Bernaudin et al. 1999, Juul et al. 1999, Siren et al. 2001) and the up-regulation of EPOR under several pathological conditions (Spandou et al. 2004, Grasso et al. 2005) suggest that this receptor is an important mediator of the 
brain's response to injury. However, it is unknown whether its expression participates in the pathogenesis of neurodegenerative diseases such as Parkinson disease (PD) and whether it has a physiological role in the ventral mesencephalon.

Because the expression of the local EPOR is sparsely investigated, the aim of this study was to elucidate the diversity of the EPOR expression and its time course in a model of PD in C57BL/6 mice.

\section{Methods}

\section{Animals and MPTP administration}

Eight-week-old male C57BL/6 mice (Experimental Animal Center, Institute of Organ Transplantation, Tongji Medical College), weighing 20-25 g, were used in all the experiments. All animal experiments were conducted in accordance with the Guide for the Care and Use of Laboratory Animals (1985), NIH, Bethesda. The mice were group-housed (five mice per cage with five compartments) in a room maintained at $20-22{ }^{\circ} \mathrm{C}$ on a 12-h light-dark cycle with food and water available ad libitum. At the beginning of the experiment, the mice (5-7 per group) received an intraperitoneal (i.p.) injection of MPTP-HCl $(30 \mathrm{mg} / \mathrm{kg}$ of free base; Sigma, St. Louis, MO, USA) in saline at $24 \mathrm{~h}$ intervals for 5 days (Dehmer et al. 2000, Hayley et al. 2004). The control group was injected with saline only at the same day. The mice were sacrificed at 1, 2, 4, 7, 14 and 21 days after the last MPTP or saline injection.

\section{Western blot analysis}

The procedure used to dissect the brain regions in mice for the MPTP studies can be performed step-bystep according to Jackson-Lewis et al. (2007). Following treatment, the mice were decapitated and the ventral midbrain (consisting of the substantia nigra, ventral tegmental area and some tissue immediately surrounding the area, excluding the basis pedunculi), striatum and frontal cortex were rapidly dissected and homogenized in ice cold-lysis buffer (50 mmol/1 Tris- $\mathrm{HCl}, \mathrm{pH} 8.0$, $100 \mathrm{~mol} / 1 \mathrm{NaCl}, 1 \mathrm{mmol} / \mathrm{l}$ EDTA, $1 \mathrm{mmol} / 1$ dithiothreitol, $1 \%$ Triton X-100, $0.1 \%$ SDS, $50 \mathrm{mmol} / 1$ sodium fluoride and $1 \mathrm{mmol} / \mathrm{l}$ sodium vanadate) containing a protease inhibitor cocktail to obtain whole cell protein. Lysates were cleared by centrifugation and protein concentration was determined by BCA kit. Equal amounts of proteins were fractionated by SDSpolyacrylamide gel electrophoresis, and transferred onto a nitrocellulose membrane. The membranes were blocked with $5 \%$ defatted milk in TBS-Tween (TBS-T) $(50 \mathrm{mM}$ Tris, $\mathrm{pH} \mathrm{7.6,} 150 \mathrm{mM} \mathrm{NaCl}, 0.1 \%$ Tween-20) and incubated with anti-EPOR rabbit polyclonal antibodies (at 1:3000 dilution, Santa Cruz Biotechnology) overnight at $4{ }^{\circ} \mathrm{C}$. The signals were detected using goat anti-rabbit horseradish peroxidase conjugated secondary antibody and enhanced chemiluminescence (ECL), then exposed to X-ray films (Fuji, Japan). The protein bands were quantified by densitometry. The densitometry values for the proteins of interest were corrected for protein loading using $\beta$-actin.

\section{Immunohistochemistry}

Animals were deeply anesthetized with sodium pentobarbital $(120 \mathrm{mg} / \mathrm{kg})$ and perfused transcardially with saline containing $0.5 \%$ sodium nitrite and $1000 \mathrm{U} / 100 \mathrm{ml}$ heparin sulfate, followed by cold $4 \%$ formaldehyde generated from paraformaldehyde in $0.1 \mathrm{M}$ sodium phosphate buffer (PBS; pH 7.2). The brains were post-fixed in the same solution for $1 \mathrm{~h}$, embedded in paraffin, and processed for histological studies. Five micrometer thick sections were cut with a microtome, deparaffinized in xylene, and rehydrated in a graded ethanol series. Slides were steamed in $0.01 \mathrm{~mol} / \mathrm{l}$ of sodium citrate buffer, $\mathrm{pH} 6$, for $10 \mathrm{~min}$ in a microwave oven. Endogenous peroxidase activity was quenched by exposing the slides to $0.3 \%$ hydrogen peroxide in methanol for $15 \mathrm{~min}$, after which the slides were rinsed in phosphate-buffered saline for a total of $10 \mathrm{~min}$. Sections were washed in PBS containing $0.5 \%$ normal goat serum for $30 \mathrm{~min}$ and incubated overnight at $4{ }^{\circ} \mathrm{C}$ with antiEPOR rabbit polyclonal antibodies (1:200; Sigma, Santa Cruz Biotechnology). Slides were rinsed three times in phosphate-buffered saline for $10 \mathrm{~min}$ and incubated for 30 min with the specific biotinylated secondary antibody (Vector Laboratories, Burlingame, CA). The slides were washed in phosphate-buffered saline and incubated for $30 \mathrm{~min}$ with the avidin-biotin complex (Vector Laboratories); they were then developed with 3, 3'-diaminobenzidine for $5 \mathrm{~min}$. Sections were mounted on gelatin coated slides, dehydrated through graded ethanols, cleared in xylene and coverslipped with permount. Slides were examined microscopically to assess the EPOR immunoreactivity. All specimens were compared with negative controls performed using normal immunoglobulin $G$ or phosphate-buffered saline as a primary antibody. An investigator blinded to the experimental groups from which each sample was 


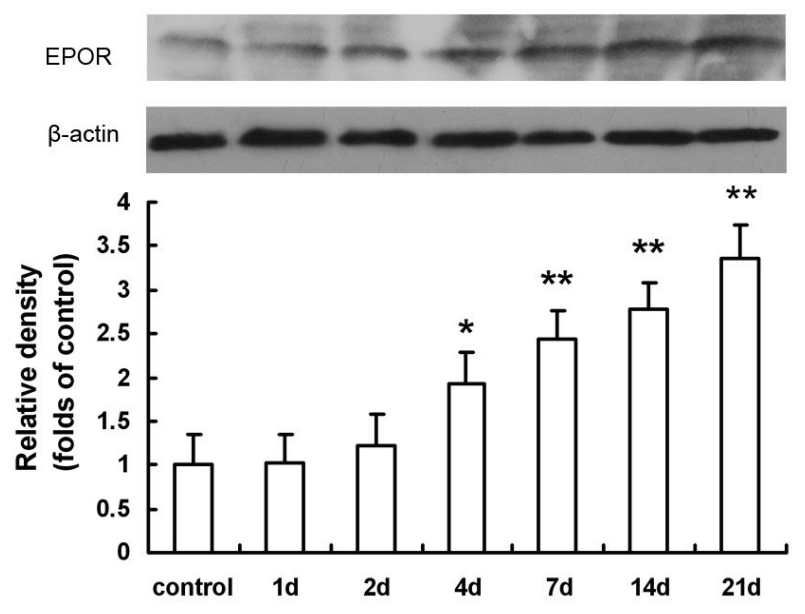

Fig. 1. Western blot analysis of EPOR in ventral mesencephalon from controls and MPTP-treated mouse. The top panel shows time course of EPO-R protein expression. EPO-R was detected in the normal ventral mesencephalon and increased after the last MPTP treatment. The bottom panel shows densitometric analysis of three separate experiments. Densitometric analysis demonstrated a significant increase by 4 days $(*, P<0.05$ vs. control; $* *, P<0.01$ vs. control).

obtained conducted this study. Data are calculated as the ratio of the number of EPOR-positive cells in the MPTPtreatment groups with that in the control group.

\section{Statistical analysis}

Data are expressed as the mean \pm S.D. Statistical analyses were performed using one-way analysis of variance (ANOVA) followed by Duncan's test for multiple comparisons. A probability of $\mathrm{P}<0.05$ was considered to be statistically significant.

\section{Results}

Time-related increase of EPOR expression in ventral mesencephalon

To analyze the effect of MPTP, EPOR protein level was examined by Western blot. In control mice, there was a baseline expression of EPOR in the ventral mesencephalon. MPTP itself, one day later, did not produce any significant changes in expression of EPOR protein in this model (Fig. 1). EPOR protein level was increased compared to control value at 2 days after MPTP treatment, although this difference was not statistical significant. In contrast, 4 days after MPTP insult, EPOR expression in the ventral mesencephalon increased 1.9-fold, indicating an up-regulation of this receptor ( $\mathrm{P}<0.05$, Fig. 1). Seven days after the last MPTP administration, EPOR in the ventral mesencephalon was even more increased compared to control value $(\mathrm{P}<0.01)$,
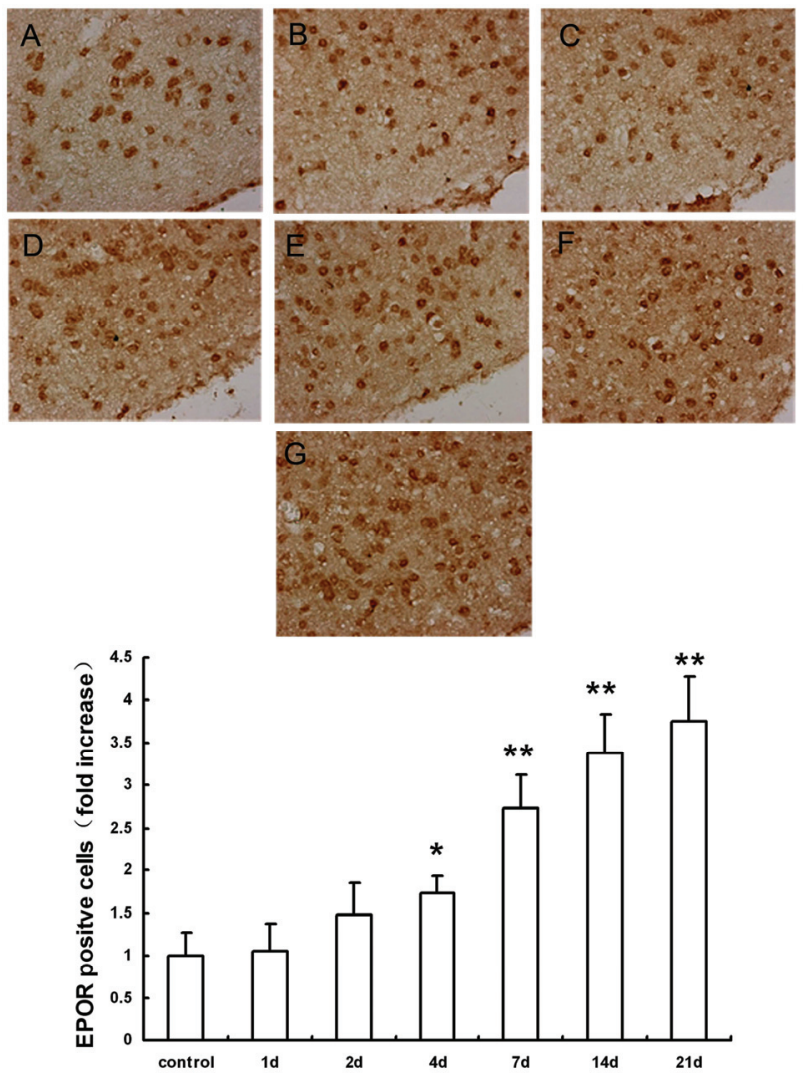

Fig. 2. Photomicrographs representing EPOR immunoreactivity in ventral mesencephalon. Compared EPO-R expression in the ventral mesencephalon at control (A), 1 (B), 2 (C), 4 (D), 7 (E), 14 (F) and 21 days (G) after the last MPTP treatment in C57BL/6 mice, immunohistochemistry section revealed that the number of EPOR positive cells was dramatically up-regulated in the ventral mesencephalon, 4 days after MPTP insult until day $21(*, P<0.05$ vs. control; **, $P<0.01$ vs. control).

and this tendency lasted to day 21 . This finding indicates that the main response of the C57BL/6 mice brain to MPTP is the up-regulation of the EPOR.

Time-related increase in number of EPORimmunostained cells in substantia nigra

One and two days after the last MPTP treatment, the number of EPOR-immunostained cells in substantia nigra was slightly increased compared with normal animals. Immunohistochemistry revealed that the number of EPOR-positive cells was dramatically up-regulated in the substantia nigra, 4 days after MPTP insult until day 21 (Fig. 2), the difference was significant $(\mathrm{P}<0.05)$.

EPOR expression and the number of EPOR-positive cells in other brain regions

In control mice, there was a baseline expression of EPOR in the striatum. MPTP itself produced slight changes in expression of EPOR protein in this model (Fig. 3), but the difference was not significant ( $\mathrm{P}>0.05)$. 


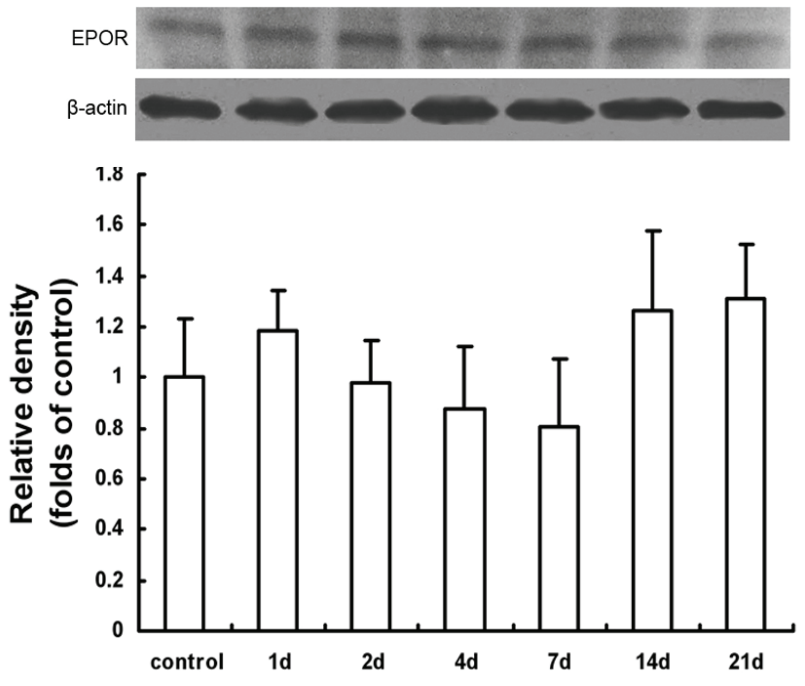

Fig. 3. Western blot analysis of EPOR in striatum from controls and MPTP-treated mouse. The top panel shows Western blot analysis of EOPR of striatum from controls and MPTP-treated mouse. The bottom panel shows densitometric analysis of three separate experiments. Statistical analysis revealed no significant differences in EPO-R expression compared with the controls.
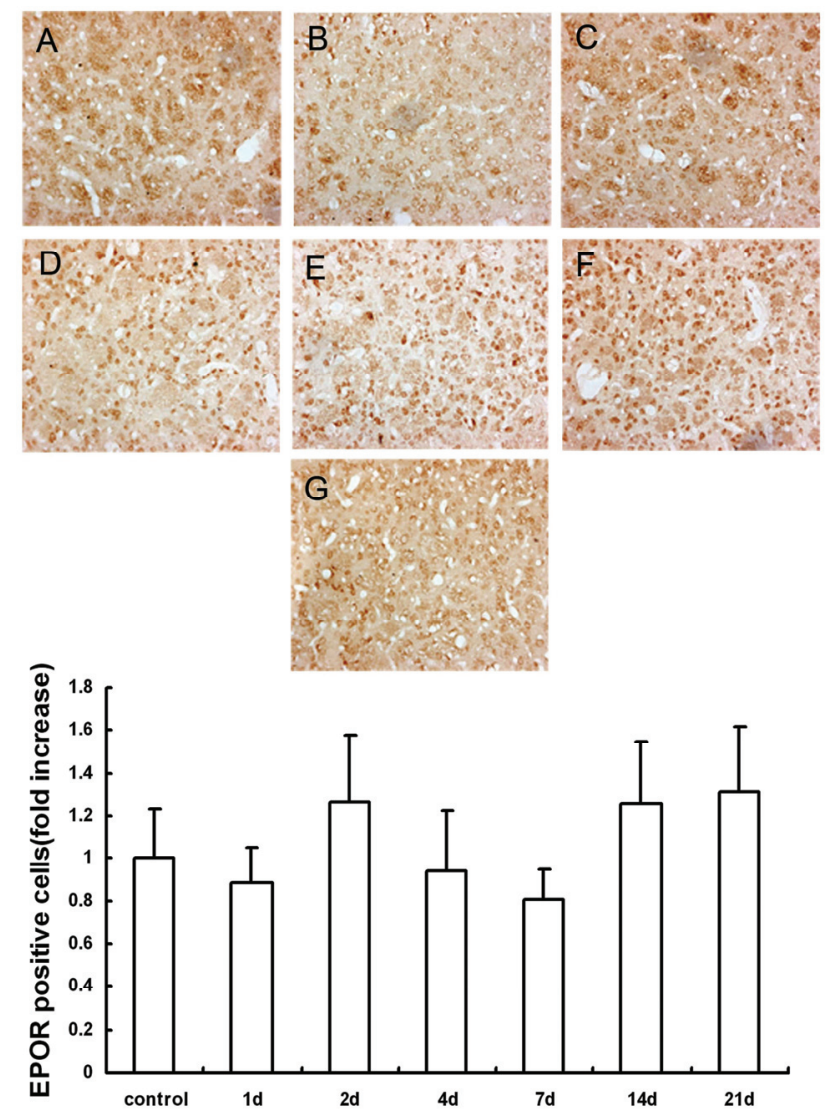

Fig. 4. Photomicrographs representing EPOR immunoreactivity in striatum. 1d (B), 2d (C), 4d (D), 7d (E), 14d (F), and 21d (G) after the last MPTP treatment in C57BL/6 mice. The number of EPOR positive cells in the striatum was not significantly different compared to normal animals $(\mathbf{A})$.

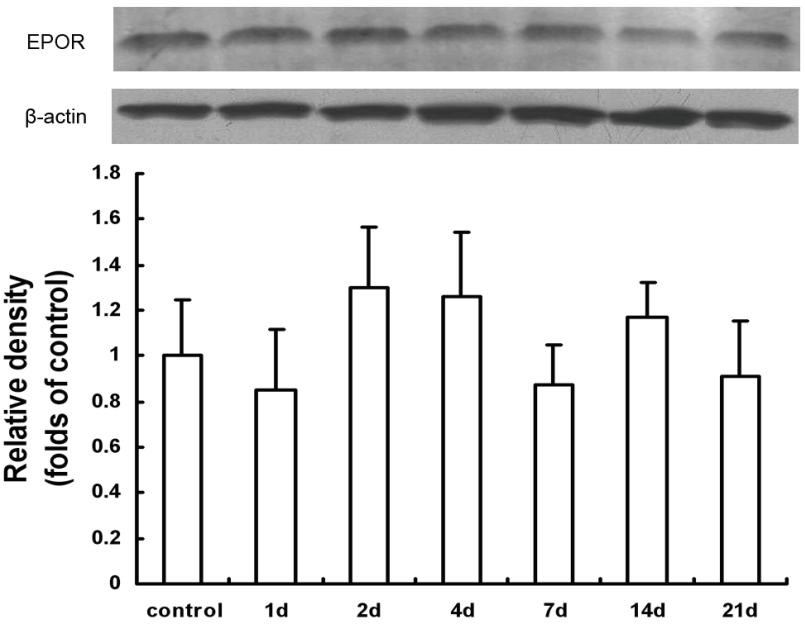

Fig. 5. Western blot analysis of EPOR in cortex from controls and MPTP-treated mouse. The top panel shows Western blot analysis of EOPR of cortex from controls and MPTP-treated mouse. The bottom panel shows densitometric analysis of three separate experiments. Statistical analysis revealed no significant differences in EPO-R expression compared with the controls.
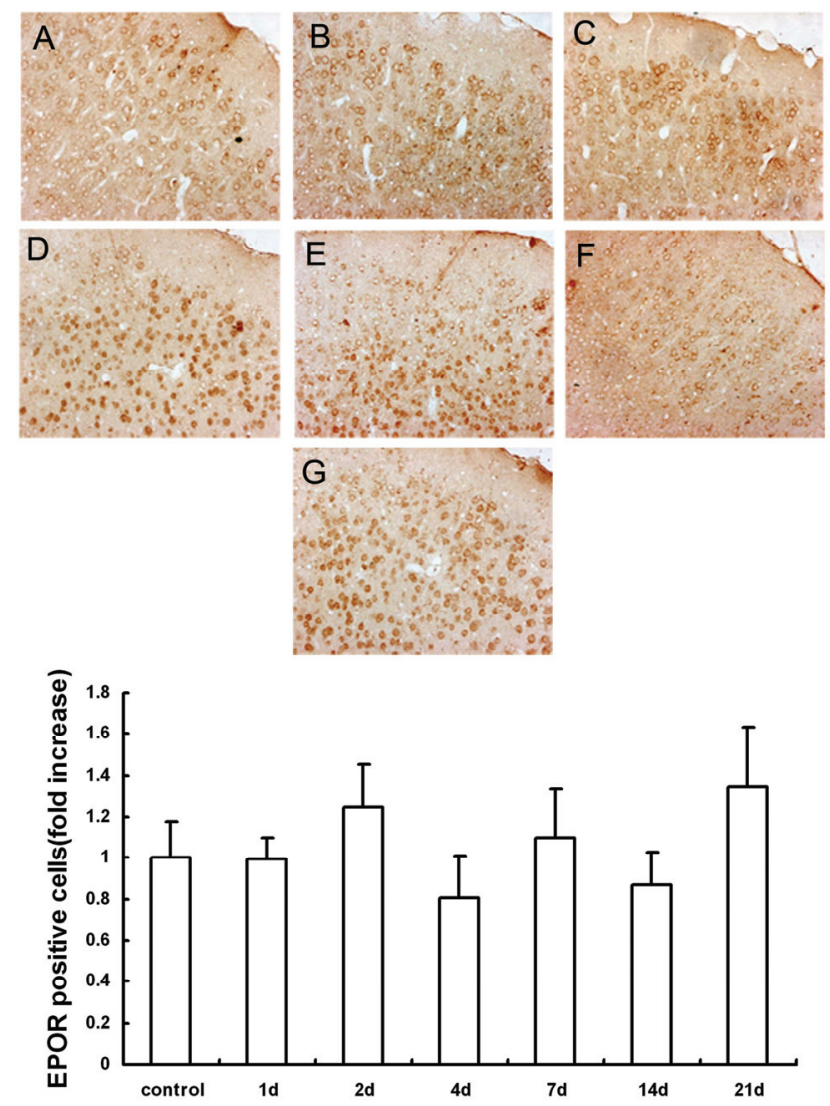

Fig. 6. Photomicrographs representing EPOR immunoreactivity in cortex. 1d (B), 2d (C), 4d (D), 7d (E), 14d (F), and 21d (G) after the last MPTP treatment in $\mathrm{C} 57 \mathrm{BL} / 6$ mice. The histological sections revealed no significant differences in EPOR positivity compared with the normal animals (A). 
EPOR-positive cells in the striatum were observed $\mathrm{n}$ the days $1,2,4,7,14$ and 21 after the last trauma. The histological sections revealed no statistical differences in EPOR positivity compared to normal animals ( $\mathrm{P}>0.05)$ (Fig.4).

The tendency of EPOR expression in cortex was similar to that in striatum. One day after the last MTPT treatment, the EPOR expression in cortex was not significantly different compared with the animals that did not undergo MPTP treatment $(\mathrm{P}>0.05)$ (Fig. 5). The same was true during subsequent time points.

At subsequent time points after MPTP injury, the numbers of EPOR-immunostained cells in cortex were not statistically different compared to those in animals that did not undergo MPTP insult ( $\mathrm{P}>0.05)$ (Fig. 6).

\section{Discussion}

Despite a large body of evidence demonstrating that exogenous EPO administered in its recombinant form exerts neurotrophic and neuroprotective actions, the precise physiological role of EPOR in the CNS remains an open question. The presence of EPOR on adult dopaminergic neurons leads to the speculation that they might play a regulatory role in neuroprotection, brain homeostasis as well as the pathogenesis of PD (Csete et al. 2004). The present study shows that EPOR is ubiquitously expressed in different brain regions of C57BL/6 mice. Protein expression of EPOR in ventral mesencephalon and the number of EPOR-positive cells in substantia nigra increased significantly in mice after MPTP lesion, whereas the expression of the same receptor was unchanged in the striatum and cortex. This is the first study to report the expression of EPOR in three brain regions in an animal model of PD.

Rapidly expanding evidences indicate that, distinct from their role in erythropoiesis, EPO-EPOR interactions confer significant cytoprotection to a host of neuronal and non-neuronal cell types within the mammalian CNS (Noguchi et al. 2007). Antioxidant, antiapoptotic, anti-inflammatory, neurotrophic, angiogenic, and synaptogenic activities have been implicated as potentially important mechanisms mediating EPO-related neuroprotection (Noguchi et al. 2007). Recent reports relevant to the present study show that EPO protects rodent dopaminergic neurons from MPTP toxicity (Genc et al. 2001, 2002, Puskovic et al. 2006).

It has been hypothesized that EPOR expression in different cell types in brain tissue parallels the occurrence of cellular responses associated with brain damage progression. Although there is a weak EPOR expression in the brain under the normal conditions, this receptor often serves as a protective mechanism under the stress or other pathophysiological conditions. Previous studies have suggested that EPOR expression may be altered in different insult processes. Expression of EPOR can be induced by hypoxia in immature and mature brains (Juul et al. 1999, Lewczuk et al. 2000). Increased expression of EPOR has also been reported following ischemia in rodent and human brain (Brines et al. 2000, Sirén et al. 2001). In the model of compressive spinal cord injury of rats, a markedly augmented expression of EPOR was observed in neurons, vascular endothelium, and glial cells after injury (Grasso et al. 2005). The immunoreactivity of EPOR was strong on blood vessels of the human epileptogenic hippocampus (Eid et al. 2004) and EPOR was found to be increased in the hippocampus after status epilepticus (Chu et al. 2008). EPOR was also up-regulated in the hippocampus and temporal cortex of patients with sporadic Alzheimer's disease and mild cognitive impairment (Assaraf et al. 2007).

PD is a debilitating neurological disorder, characterized by a loss of dopaminergic neurons located in substantia nigra pars compacta. A neurotoxin MPTP, that selectively damages dopaminergic cells in the substantia nigra, has been used to generate an animal model of PD (Langston et al. 1983, Heikkila et al. 1984). The increased expression of EPOR in the ventral mesencephalon, an area particularly susceptible to MPTP-related damage, suggests that this up-regulation of expression of EPOR can be interpreted as a consequence of the self-protective, compensatory reaction of the body to exogenous or endogenous impairments.

The results of our current study suggest that the induction of EPOR may contribute to the ongoing pathogenesis, and raise the exciting possibility that EPOR in the ventral mesencephalon, could provide a target for the treatment of PD by erythropoietin. Although further studies on functional features of EPOR and the time courses of EPOR expression in neurons and glia are needed, the data of the present study provided insights into neurotoxin-related changes in trophic support as well as basic knowledge about PD.

\section{Conflict of Interest}

There is no conflict of interest. 


\section{Acknowledgements}

This study was supported by a grant from the Program of
National Natural Science Foundation of China (No. 30570627/C030307).

\section{References}

ASSARAF MI, DIAZ Z, LIBERMAN A, MILLER WH JR, ARVANITAKIS Z, LI Y, BENNETT DA, SCHIPPER HM: Brain erythropoietin receptor expression in Alzheimer disease and mild cognitive impairment. J Neuropathol Exp Neurol 66: 389-398, 2007.

BERNAUDIN M, MARTI HH, ROUSSEL S, DIVOUX D, NOUVELOT A, MACKENZIE ET, PETIT E: A potential role for erythropoietin in focal permanent cerebral ischemia in mice. $J$ Cereb Blood Flow Metab 19: 643-651, 1999.

BRINES ML, GHEZZI P, KEENAN S, AGNELLO D, DE LANEROLLE NC, CERAMI C, ITRI LM, CERAMI A: Erythropoietin crosses the blood-brain barrier to protect against experimental brain injury. Proc Natl Acad Sci USA 97: 10526-10531, 2000.

CHONG ZZ, LIN SH, KANG JQ, MAIESE K: Erythropoietin prevents early and late neuronal demise through modulation of Akt1 and induction of caspase 1, 3, and 8. J Neurosci Res 71: 659-669, 2003.

CHU K, JUNG KH, LEE ST, KIM JH, KANG KM, KIM HK, LIM JS, PARK HK, KIM M, LEE SK, ROH JK: Erythropoietin reduces epileptogenic processes following status epilepticus. Epilepsia 49: 1723-1732, 2008.

CSETE M, RODRIGUEZ L, WILCOX M, CHADALAVADA S: Erythropoietin receptor is expressed on adult rat dopaminergic neurons and erythropoietin is neurotrophic in cultured dopaminergic neuroblasts. Neurosci Lett 359: 124-126, 2004.

DEHMER T, LINDENAU J, HAID S, DICHGANS J, SCHULZ JB: Deficiency of inducible nitric oxide synthase protects against MPTP toxicity in vivo. J Neurochem 74: 2213-2216, 2000.

EID T, BRINES ML, CERAMI A, SPENCER DD, KIM JH, SCHWEITZER JS, OTTERSEN OP, DE LANEROLLE NC: Increased expression of erythropoietin receptor on blood vessels in the human epileptogenic hippocampus with sclerosis. J Neuropathol Exp Neurol 63: 73-83, 2004.

GRASSO G, SFACTERIA A, PASSALACQUA M, MORABITO A, BUEMI M, MACRI B, BRINES ML, TOMASELLO F: Erythropoietin and erythropoietin receptor expression after experimental spinal cord injury encourages therapy by exogenous erythropoietin. Neurosurgery 56: 821-827, 2005.

GENC S, KURALAY F, GENC K, AKHISAROGLU M, FADILOGLU S, YORUKOGLU K, FADILOĞLU M, GURE A: Erythropoietin exerts neuroprotection in 1-methyl-4-phenyl-1, 2, 3, 6-tetrahydropyridine-treated C57/BL mice via increasing nitric oxide production. Neurosci Lett 298: 139-141, 2001.

GENC S, AKHISAROGLU M, KURALAY F, GENC K: Erythropoietin restores glutathione peroxidase activity in 1-methyl-4-phenyl-1, 2, 5, 6-tetrahydropyridine-induced neurotoxicity in C57BL mice and stimulates murine astroglial glutathione peroxidase production in vitro. Neurosci Lett 321: 73-76, 2002.

HAYLEY S, CROCKER SJ, SMITH PD, SHREE T, JACKSON-LEWIS V, PRZEDBORSKI S, MOUNT M, SLACK R, ANISMAN H, PARK DS: Regulation of dopaminergic loss by Fas in a 1-methyl-4-phenyl-1,2,3,6tetrahydropyridine model of Parkinson's disease. J Neurosci 24: 2045-2053, 2004.

HEIKKILA RE, HESS A, DUVOISIN RC: Dopaminergic neurotoxicity of 1-methyl-4-phenyl-1,2,3,6tetrahydropyridine in mice. Science 225: 1451-1453, 1984.

JACKSON-LEWIS V, PRZEDBORSKI S: Protocol for the MPTP mouse model of Parkinson's disease. Nat Protoc 2: 141-151, 2007.

JUNK AK, MAMMIS A, SAVITZ SI, SINGH M, ROTH S, MALHOTRA S, ROSENBAUM PS, CERAMI A, BRINES M, ROSENBAUM DM: Erythropoietin administration protects retinal neurons from acute ischemiareperfusion injury. Proc Natl Acad Sci USA 99: 10659-10664, 2002.

JUUL SE, YACHNIS AT, ROJIANI AM, CHRISTENSEN RD: Immunohistochemical localization of erythropoietin and its receptor in the developing human brain. Pediatr Dev Pathol 2: 148-158, 1999.

LANGSTON JW, BALLARD P, TETRUD JW, IRWIN I: Chronic parkinsonism in humans due to a product of meperidine-analog synthesis. Science 219: 979-980, 1983. 
LEWCZUK P, HASSELBLATT M, KAMROWSKI-KRUCK H, HEYER A, UNZICKER C, SIRÉN AL, EHRENREICH H: Survival of hippocampal neurons in culture upon hypoxia: effect of erythropoietin. NeuroReport 11: 3485-3488, 2000.

MARTI HH, WENGER RH, RIVAS LA, STRAUMANN U, DIGICAYLIOGLU M, HENN V, YONEKAWA Y, BAUER C, GASSMANN M: Erythropoietin gene expression in human monkey and murine brain. Eur $J$ Neurosci 8: 666-676, 1996.

MORISHITA E, MASUDA S, NAGAO M, TASUDA Y, SASAKI R: Erythropoietin receptor is expressed in rat hippocampal and cerebral cortical neurons, and erythropoietin prevents in vitro glutamate-induced neuronal death. Neuroscience 76: 105-116, 1997.

NOGUCHI CT, ASAVARITIKRAI P, TENG R, JIA Y: Role of erythropoietin in the brain. Crit Rev Oncol Hematol 64: 159-171, 2007.

PUSKOVIC V, WOLFE D, WECHUCK J, KRISKY D, COLLINS J, GLORIOSO JC, FINK DJ, MATA M: HSVmediated delivery of erythropoietin restores dopaminergic function in MPTP-treated mice. Mol Ther 14: 710$715,2006$.

VILLA P, BIGINI P, MENNINI T, AGNELLO D, LARAGIONE T, CAGNOTTO A, VIVIANI B, MARINOVICH M, CERAMI A, COLEMAN TR, BRINES M, GHEZZI P: Erythropoietin selectively attenuates cytokine production and inflammation in cerebral ischemia by targeting neuronal apoptosis. $J$ Exp Med 198: 971-975, 2003.

SHANG Y, WU Y, YAO S, WANG X, FENG D, YANG W: Protective effect of erythropoietin against ketamineinduced apoptosis in cultured rat cortical neurons: involvement of PI3K/Akt and GSK-3 beta pathway. Apoptosis 12: 2187-2195, 2007.

SIREN AL, KNERLICH F, POSER W, GLEITER CH, BRUCK W, EHRENREICH H: Erythropoietin and erythropoietin receptor in human ischemic/hypoxic brain. Acta Neuropathol 101: 271-276, 2001.

SPANDOU E, PAPOUTSOPOULOU S, SOUBASI V, KARKAVELAS G, SIMEONIDOU C, KREMENOPOULOS G, GUIBA-TZIAMPIRI O: Hypoxia-ischemia affects erythropoietin and erythropoietin receptor expression pattern in the neonatal rat brain. Brain Res 1021: 167-172, 2004.

WU Y, SHANG Y, SUN S, LIANG H, LIU R: Erythropoietin prevents PC12 cells from 1-methyl-4-phenylpyridinium ion-induced apoptosis via the Akt/GSK-3beta/caspase-3 mediated signaling pathway. Apoptosis 12: 1365$1375,2007 \mathrm{a}$.

WU Y, SHANG Y, SUN S, LIU R: Antioxidant effect of erythropoietin on 1-methyl-4-phenylpyridinium-induced neurotoxicity in PC12 cells. Eur J Pharmacol 14: 47-56, $2007 \mathrm{~b}$. 